

\title{
Dose-dependent neuroprotective effect of the JNK inhibitor Brimapitide in 5xFAD transgenic mice
}

Baptiste Porte, Gwendolyn Marguerit, Sylvie Thomasseau, Claire Paquet, Jacques Hugon

\section{- To cite this version:}

Baptiste Porte, Gwendolyn Marguerit, Sylvie Thomasseau, Claire Paquet, Jacques Hugon. Dosedependent neuroprotective effect of the JNK inhibitor Brimapitide in 5xFAD transgenic mice. Brain Research, 2020, 1727, pp.146587 -. 10.1016/j.brainres.2019.146587 . hal-03488388

\section{HAL Id: hal-03488388 \\ https://hal.science/hal-03488388}

Submitted on 21 Dec 2021

HAL is a multi-disciplinary open access archive for the deposit and dissemination of scientific research documents, whether they are published or not. The documents may come from teaching and research institutions in France or abroad, or from public or private research centers.
L'archive ouverte pluridisciplinaire HAL, est destinée au dépôt et à la diffusion de documents scientifiques de niveau recherche, publiés ou non, émanant des établissements d'enseignement et de recherche français ou étrangers, des laboratoires publics ou privés.

\section{(c) (1) $\$$}

Distributed under a Creative Commons Attribution - NonCommerciall 4.0 International 


\section{Dose-dependent neuroprotective effect of the JNK inhibitor Brimapitide in}

\section{5xFAD transgenic mice}

Baptiste Porte ${ }^{1,2, *}$, Gwendolyn Marguerit ${ }^{1}$, Sylvie Thomasseau ${ }^{1}$, Claire Paquet ${ }^{1,2}$, Jacques Hugon $^{1,2}$

${ }^{1}$ Université de Paris, INSERM UMR-S 1144, F-75006 Paris, France

${ }^{2}$ Centre de Neurologie Cognitive, AP-HP, Hôpital Fernand-Widal, F-75475 Paris, France.

Baptiste Porte, BP, baptiste.porte@inserm.fr

Gwendolyn Marguerit, GM, gwendolyn.marguerit@inserm.fr

Sylvie Thomasseau, ST, sylvie.thomasseau@inserm.fr

Claire Paquet, CP, claire.paquet@inserm.fr

Jacques Hugon, JH, jacques.hugon@inserm.fr

*Corresponding author:

Baptiste Porte, baptiste.porte@inserm.fr

Neurodiderot - Inserm UMR 1141

Hôpital Robert-Debré

Bâtiment Ecran/Bingen, Point Jaune - 3ème étage

48, boulevard Sérurier, 75019 Paris, France

Tel : +33 (0) 6.11.31.68.87 


\section{ABSTRACT}

Alzheimer's disease $(A D)$ is a neurodegenerative disease mainly affecting old people.

According to the "amyloid cascade hypothesis", the accumulation of A $\beta$ oligomers could lead to kinase activation and tau phosphorylation. Activated kinases include c-Jun $\mathrm{N}$-terminal kinase (JNK) and previous studies highlighted the beneficial effects of the JNK-specific inhibitor Brimapitide $(10 \mathrm{mg} / \mathrm{kg})$ in 5xFAD transgenic mice. Our aim was to evaluate the effects of decreasing doses of Brimapitide on cognition and neurodegeneration in early treated 5XFAD mice.

Three month-old 5xFAD were intravenously treated for 6 months with either Brimapitide (3 $\mathrm{mg} / \mathrm{kg}$ or $0.3 \mathrm{mg} / \mathrm{kg}$ ) or Nacl. Cognition and amyloid burden, neuronal and synaptic impairments were evaluated. Low doses of Brimapitide $(0.3 \mathrm{mg} / \mathrm{kg})$ reduced neuronal degeneration and improved cognition in treated mice compared to non-treated mice. Amyloid burden and synaptic degeneration only decreased with the $3 \mathrm{mg} / \mathrm{kg}$ dose.

This JNK inhibitor can afford neuroprotection but with a differential effect on amyloid deposition in 5xFAD mice. Brimapitide might partially prevent ongoing neurodegeneration in 5XFAD mice.

KEYWORDS: Alzheimer's disease; mice; JNK inhibitor; dose ranging; Brimapitide 


\section{INTRODUCTION}

Alzheimer's disease $(A D)$ is the most common form of dementia mostly affecting aging population. In 2018, almost 44 million people in the world suffered from dementia (GBD 2016 Dementia Collaborators. 2019). This number is estimated to triple by 2050 (Patterson 2018). The three mains pathological features of $A D$ are: i) extra-neuronal accumulation of $\beta$-amyloid peptides $(A \beta)$ aggregating into senile plaques, ii) intra-neuronal accumulation of hyperphosphorylated tau proteins and iii) neuronal death associated with synaptic loss and neuroinflammation (Duyckaerts et al. 2009). Memory troubles are often the first clinical sign followed by aphasia, apraxia, agnosia and behavioral disturbances.

The "amyloid cascade hypothesis" describes the pathophysiological mechanism of AD linked to a dysregulation of $A \beta$ peptides accumulation (Hardy et al. 1992). The amyloid precursor protein (APP) is first cleaved by $\beta$-site APP cleaving enzyme (BACE1) producing: i) a soluble form of APP and, ii) a membrane-linked fragment. Then, $\gamma$-secretase cleaves this fragment into $A \beta$ peptides of either $40\left(A \beta_{40}\right)$ or $42\left(A \beta_{42}\right)$ amino acids. $A \beta_{40}$ is the most common form of $A \beta$ peptide whereas $A \beta_{42}$ is present in lower quantity at physiological state. In familial $A D$ cases, mutations identified in patients affect genes coding for APP or $\gamma$-secretase, modifying the balance between $A \beta_{40}$ and $A \beta_{42}$. Accumulation of $A \beta_{42}$ leads to the formation of neurotoxic $A \beta$ oligomers that aggregate into insoluble senile plaques and cause ultimately a cascade of brain lesions responsible for cognitive decline (Lane et al. 2018). Amyloid-induced kinase activation is a common feature of this "cascade hypothesis" and could lead to tau phosphorylation and neuronal demise (Ebenezer et al. 2010, Kim et al. 2015, Hugon et al. 2017).

Several studies have demonstrated the implication of c-Jun N-terminal kinase (JNK), a serinethreonine kinase of the mitogen activated protein kinase family, notably in the pathological process of AD (Kim and Choi 2015). JNK participate in the development of inflammation and neurodegeneration (Morishima et al. 2001, Zhu et al. 2001, Savage et al. 2002, Tamagno et al. 2005, Colombo et al. 2009, Sclip et al. 2011, Sclip et al. 2014, Gourmaud et al. 2015). Among the three isoforms (JNK1, JNK2 and JNK3), JNK 3 is expressed rather specifically in the brain. Cerebrospinal fluid JNK3 as well as PKR levels are enhanced in AD patients and correlate with cognitive impairments (Dumurgier et al. 2013, Gourmaud et al. 2015). JNK is 
activated in AD brains and can be associated with $A \beta$ accumulation (Savage et al. 2002). In addition, JNK can phosphorylate APP on threonine 668 leading to an augmented A $\beta$ production and can increase BACE1 mRNA expression (Standen et al. 2001, Tamagno et al. 2005).

Previous works have shown that JNK inhibition is an appropriate tool for studying signaling pathways at a physiological state (Wei et al. 2014, Jing et al. 2019) and for assessing therapeutic intervention in various pathologies (Morishima et al. 2001, Borsello et al. 2003, Sclip et al. 2014, Yarza et al. 2015). Among specific JNK inhibitors, Brimapitide (XG-102) is a small inhibitory peptide already proposed in clinical development for other diseases (Chiquet et al. 2017, Eshraghi et al. 2018, Staecker et al. 2019). In preclinical studies, Brimapitide has demonstrated neuroprotective effects notably in cerebral ischemia (Borsello et al. 2003) and in AD models, by decreasing APP phosphorylation and A $\beta$ production (Colombo et al. 2009, Ploia et al. 2011, Sclip et al. 2011). Moreover, in vitro studies have revealed that JNK inhibition, including with Brimapitide, was able to reduce $A \beta$ toxicity or neurodegeneration of cultured cortical neurons (Repici et al. 2009, Gourmaud et al. 2016). In 2018, Gourmaud et al. reported that a 6-month treatment with Brimapitide at $10 \mathrm{mg} / \mathrm{kg}$ improved cognition and reduce amyloid burden and neurodegeneration in 5xFAD mice (Gourmaud et al. 2018). Thus, a phase 1 study in healthy human volunteers has already shown that the intravenous (IV) infusion of Brimapitide at 10, 40 and $80 \mu \mathrm{g} / \mathrm{kg}$ was well-tolerated (Deloche et al. 2014).

5xFAD mice are genetically engineered animals that express five human mutations, three on APP and two on presenilin-1 (PS1), one of the 4 units of $y$-secretase. 5xFAD mouse is considered as an aggressive transgenic $A D$ model, as $A \beta$ accumulation and plaque formation start earlier than in many other AD models (Webster et al. 2014). Indeed, Oakley et al. (2016) described in 5xFAD mice early cognitive impairments (at 3 months-old) associated with $A \beta$ accumulation from 1.5 month onward, synaptic markers progressively decreasing with aging (notably PSD-95) and a peak of neuronal loss at 6 month. Both increased $A \beta$ load and loss of PSD-95 labelling have been shown in various AD mice models (Dinamarca et al. 2012) and will be used in this study as markers of brain lesions.

The aim of our study was to evaluate the effect of Brimapitide at lower doses than $10 \mathrm{mg} / \mathrm{kg}$ in 5XFAD mice. We wanted to carry out a dose-effect study to determine the most appropriate starting concentrations for future human trials. The 5XFAD mice were IV treated 
for 6 months with Brimapitide at $3 \mathrm{mg} / \mathrm{kg}, 0.3 \mathrm{mg} / \mathrm{kg}$ or with $\mathrm{Nacl}$. The results show that 3 $\mathrm{mg} / \mathrm{kg}$ Brimapitide efficiently decreases $A \beta$ burden while $0.3 \mathrm{mg} / \mathrm{kg}$ reduces the neuronal degeneration in association with improved cognition in 5xFAD mice.

\section{RESULTS}

\subsection{Brimapitide improves cognition of $5 x F A D$ mice at $0.3 \mathrm{mg} / \mathrm{kg}$}

The effect of Brimapitide on cognition was assessed with the Y-maze test. Mice were placed in the center area of the Y-maze and allowed to explore freely for 8 minutes. Entries in each arm and in the center area were automatically recorded. These data were used to calculate alternation percentage based on the ability of animal to do triades of entries without reentering in a just-visited arm. The task requires the animal to navigate in a maze (spatial memory) and remembering which arm it has previously visited (procedural working memory). 5xFAD mice treated with Nacl revealed a statistically lower alternation percentage than control mice. Regarding the effect of Brimapitide, only $0.3 \mathrm{mg} / \mathrm{kg}$ treated 5xFAD mice showed a statistically significant improved cognition compared both to $\mathrm{Nacl}$ and $3 \mathrm{mg} / \mathrm{kg}$ treated counterpart (Fig. 1). Treatment at $3 \mathrm{~m} / \mathrm{kg}$ failed to improve cognition.

In addition to Y-maze, we also used contextual fear conditioning, assessing associative memory: association of an aversive stimuli (electrical foot shock) with a particular context (a test chamber with black and white stripes on the walls). Cognition was evaluated by the number of freezing episodes and total freezing time. No effect of Brimapitide treatment was observed in this test (Supp data and Supp Fig 1)

\subsection{Brimapitide is able to attenuate neuronal degeneration}

Fluorojade (FJ) is a green fluorescent dye that labels degenerating neurons. Effect on neurodegeneration (labeled neurons) was evaluated by fluorescence imaging in the subiculum that is the most and earliest affected region of the hippocampus in 5XFAD mice. No FJ staining was detected in control mice (Fig 2A, picture only). Only in $0.3 \mathrm{mg} / \mathrm{kg}$ treated mice a statistically lower FJ labeling was detected as compared to Nacl treated mice (Fig 2A). 
This significant effect of the lowest dose was also observed when results were compared to $3 \mathrm{mg} / \mathrm{kg}$ treated mice (Fig. $2 \mathrm{~A}$ )

We then choose to analyze synaptic degeneration by assessing the levels of PSD95, a post synaptic protein, known to have decreased brain levels during the pathology evolution in $A D$ mice models (Dinamarca et al. 2012). We realized immunoblots on extracts of total cortex and hippocampus of each mice group with an antibody directed against PSD-95. Only in total cortex of $3 \mathrm{mg} / \mathrm{kg}$ treated mice PSD 95 levels were significantly higher than in Nacl treated mice (Fig. 2B). In the hippocampus, no statistically significant changes were observed with treatment (data not shown).

\subsection{Amyloid burden is reduced by Brimapitide at $3 \mathrm{mg} / \mathrm{kg}$.}

Finally, the effect of Brimapitide on amyloid burden, a characteristic feature of $A D$ pathology, was assessed by quantified immunohistochemistry using an antibody against the A4 epitope of APP which is specific for soluble $A \beta$. No staining was found in control mice (Fig $3 A$ and $3 B$, pictures only). In 5xFAD mice a significantly higher labeling was observed compared to control mice, both in the cortex and in the subiculum (data not shown). The amyloid load was statistically reduced in $3 \mathrm{mg} / \mathrm{kg}$ treated 5xFAD mice compared to Nacltreated and to $0.3 \mathrm{mg} / \mathrm{kg}$ treated 5xFAD mice. This effect was found in the cortex (Fig. 3A) and the subiculum (Fig. 3B).

\section{DISCUSSION}

Our study demonstrates that in 5xFAD mice, Brimapitide can modulate cognitive decline and improved AD brain lesions at lower doses than previously described (Gourmaud et al. 2018). In details, the $3 \mathrm{mg} / \mathrm{kg}$ dose was able to reduce synaptic loss (PSD95) in the cortex and the amyloid load in the cortex and in the subiculum. 5xFAD mice treated with $0.3 \mathrm{mg} / \mathrm{kg}$ dose showed improvement in the Y-maze task (alternation percentage) and decreased neuronal degeneration revealed by FJ. Treatment started at 3 months of age, a pathological stage with limited brain lesions which could correspond to a human $\mathrm{MCl}$ due to $\mathrm{AD}$ stage and the 
pharmacological processes could somewhat correspond to a preventive approach of mildly affected 5xFAD mice.

The first step of our study was to determine the appropriate minimum doses able to ensure protective effect of Brimapitide in 5xFAD mice as an initial phase to envision future human trials with this drug (Gourmaud et al. 2018). We have determined two concentrations at 3 $\mathrm{mg} / \mathrm{kg}$ and $0.3 \mathrm{mg} / \mathrm{kg}$, according to a practical guide for dose conversion (Nair et al. 2016), that are able to modulate cognition, amyloid load, synaptic and neuronal demises in 5xFAD mice. The first question that can be addressed is why the $3 \mathrm{mg} / \mathrm{kg}$ dose did not reduced cognitive alteration or synaptic loss as observed with the $0.3 \mathrm{mg} / \mathrm{kg}$ dose ? Although all mice were similar and genetically controlled as in our previous report, one explanation could be linked to the known genetic and/or epigenetic heterogeneity in 5xFAD mice (Grinan-Ferre et al. 2016). We have assessed repetitively the genetic background of the 5xFAD mice but we could not evaluate in all mice the five inserted mutations responsible for brain lesions as well as epigenetic modifications. It is possible that due to this heterogeneity, a genetic drift may have modified the magnitude of abnormal metabolisms leading to neuropathological lesions and altered cognition. Using the same compound in TgCRND8 AD mice, the dose of $22 \mathrm{mg} / \mathrm{kg}$ was needed to be efficient at modulating cognition and brain lesions suggesting that a variability of response to Brimapitide occurs as well in various AD transgenic models (Sclip et al. 2011). Moreover, epigenetics factors can also modulate the pathological features of $A D$ mice model. Devi et al. (2010) reported that behavioral stress can modulate $A \beta$ production in hippocampus. So it is not impossible that variable stress may have altered the level of $A \beta$ in 5xFAD brain and so can be accounted for the observed heterogeneity.

No effect on cognition was detected with the fear conditioning test. The doses used could be too low for inducing any effect in this paradigm as we previously described a reduction of cognitive deficit with a $10 \mathrm{mg} / \mathrm{kg}$ treatment (Gourmaud et al. 2018).

The second step of our research was to determine if Brimapitide was able to reduce neurodegeneration at reduced doses. We have shown that $0.3 \mathrm{mg} / \mathrm{kg}$ could reduce the FJ staining after 6 months of administration in the subiculum of transgenic animals. A neuroprotective action of Brimapitide was demonstrated in earlier works but with higher concentrations at 22 and $10 \mathrm{mg} / \mathrm{kg}$ in AD models (Sclip et al. 2011, Gourmaud et al. 2018). The role of JNK in neuronal death has been already well documented in various models of 
brain disorders and our results emphasize the concept that JNK inhibition is a future possible target in AD (Sclip et al. 2014, Yarza et al. 2015).

The third notable point of our study is the dissociation between the effect of Brimapitide on amyloid burden and cognitive improvement in 5xFAD mice. This finding was already detected in our previous report using a $10 \mathrm{mg} / \mathrm{kg}$ dose for 6 months (Gourmaud et al. 2018) and was confirmed in this report using a $0.3 \mathrm{mg} / \mathrm{kg}$ dose for 6 months. With this concentration, the neuroprotective effect was not associated with a reduction of the amyloid burden. This result implies that Brimapitide can attenuate detrimental neuronal pathways independently of the concomitant neurotoxic role of $A \beta$ species. It is known that JNK is implicated in neuronal death, synaptic plasticity, inflammation and memory and the observed effects of Brimapitide on neurodegeneration and cognition may well be related to the direct consequences of JNK inhibition by Brimapitide in neurons but also in glial cells (Kaminska et al. 2009, Coffey 2014). Nevertheless, this dissociation can also be interpreted in keeping with the involvement of JNK in the pathological cascade of AD (Kim and Choi 2015). Moreover, as factors like mitochondrial dysfunction through calcium efflux impairments can also contribute to disease evolution (Jadiya et al. 2019), JNK inhibition alone may not be sufficient to rescue all abnormal signalings present in 5xFAD mice.

A previous works has shown that Brimapitide is able to cross the blood brain barrier after intraperitoneal (IP) injection and is present in the brain for at least one week with an increased concentration as compared to $24 \mathrm{~h}$ post injection (Davoli et al. 2014). To our knowledge no information is available concerning the brain long lasting presence of Brimapitide beyond one week after IV or IP administration. A limitation of our study is that mice were IV injected every 3 weeks to comply with our previous study. This rhythm of administration could explain the absence of modification of the ratio phosphorylated JNK/total JNK observed in total cortex and hippocampus of treated d 5xFAD mice (Supplementary data and Supplementary Fig 2). The remaining action of Brimapitide could be drastically decreased after 3 weeks. Future evaluations of the concentrations of Brimapitide in the brain of experimental animals will be necessary to determine the slowly decreasing cerebral levels after a single IV or IP administration. Similarly, an assessment of the cerebrospinal concentrations of Brimapitide after IV infusion will be needed in human trials. 
In conclusion, our study has demonstrated that low doses of Brimapitide can have an effect on neurodegeneration, amyloidosis and cognition in the 5xFAD mice. 5xFAD mice were treated at an early stage of the evolution of brain lesions and Brimapitide seems to partially prevent ongoing abnormal neuronal processes leading to neurodegeneration. Futures researches will be needed to determine if the early reduction of JNK activity, experimentally and in humans, is able to interfere with the course of abnormal brain lesions.

\section{EXPERIMENTAL PROCEDURE}

\subsection{Mice and treatment}

This study project (\#9035 2017020611339643) was submitted to $\mathrm{n}^{\circ} 3$ CECCO Committee at Cryopreservation, Distribution, Transgenesis and Archiving (license D-45-234-6) and $\mathrm{n}^{\circ} 5$ Charles Darwin Committee at Brain and Spine Institute, Paris, France (license A75-13-19). Committees and the Higher Education, Research and Innovation French Ministry green lighted it (agreement APAFIS \#9035-2017020611339643 v2). All experiments followed animal handling guidelines from the French Agriculture and Forestry Ministry (decree 87849) and EC Directive 86/609/EEC for animal experiments.

5xFAD are C57BI6 mice with an artificial transgene expressing the K670N/M671L, 1716V, and V717I mutations of human APP gene, and the M146L and L286V mutations of human PS1 gene. Three-month-old 5xFAD males were randomly assigned to a treatment group $(n=7-12$ animals): Nacl, XG-102 (Brimapitide) at $3 \mathrm{mg} / \mathrm{kg}$ or at $0.3 \mathrm{mg} / \mathrm{kg}$. Each group was treated during 6 month, reaching a total of 9 injections in the caudal vein. Brimapitide (XG-102 peptide, Xigen S.A., Switzerland) was reconstituted in $\mathrm{NaCl}(0.9 \%, \mathrm{~B}$. Braun, France) and diluted at the corresponding concentrations. Doses were calculated according to dose conversion guide between humans and animals (Nair et al. 2016). C57BI6 wild type mice were used as control mice (CT, Janvier Laboratories, Saint Brethevin, France). Animals were housed in standard cages ( 5 or less mice per cage) in a controlled environment $\left(23^{\circ} \mathrm{C}, 53 \%\right.$ humidity, and $12 \mathrm{~h} / 12 \mathrm{~h}$ light cycle). Mice had ad libitum access to food and water. All the breeding and injections were done in Cryopreservation, Distribution, Transgenesis and Archiving (CDTA, Orleans, France). 


\subsection{Behavioral tests}

Behavioral assessments took place 3 weeks after the last injection due to the sanitary requirements of the preclinical functional exploration unit PHENOPARC (Brain \& Spine Institute, Pitié-Salpêtrière Hospital, Paris, France). ANY-Maze software (v5.2, Stoeling) was used to recorded and analyzed behavior.

The Y-maze test evaluated spatial and procedural working memory (hippocampus specific). It consisted in a $Y$ shaped maze $(27 \mathrm{~cm}$ length, $7 \mathrm{~cm}$ width and $20 \mathrm{~cm}$ height for each arm). Each mouse explored it freely during 8 minutes. Memory was evaluated by the alternation percentage: number of consecutive entry in 3 different arms/(total number of entry -2$) * 100$.

\subsection{Brain tissue and protein preparation}

Mice were anesthetized with $0.15 \mathrm{ml}$ of sodium pentobarbital (Ceva, Paris, France). A quick intra-cardiac perfusion of phosphate buffer saline (PBS, Merck, Darmstadt, Germany) was performed for cleaning the circulatory system. Brain was obtained through dissection and separated in two hemispheres.

The left one was fixed with paraformaldehyde 4\% diluted in PBS (PFA, Merck, Darmstadt, Germany) for 24 hours at $4^{\circ} \mathrm{C}$, then post-fixed in paraformaldehyde $0.4 \%$ for a week at $4^{\circ} \mathrm{C}$. The right hemisphere was dissected to obtain the total cortex and the hippocampus. Both structures were flash-freeze in liquid nitrogen and stored at $-80^{\circ} \mathrm{C}$. Proteins were extracted from total cortex and hippocampus samples with completed RIPA buffer (RIPA added with $1 \mu \mathrm{M}$ calyculin A, $1 \mathrm{mM}$ Na3VO4 and a protease inhibitor cocktail; Merck, Darmstadt, Germany) then sonicated ( 1 min, 55\% of maximal intensity, Sonopuls, Bandelin, Berlin, Germany). Protein concentration was measured with the BiCinchoninic acid assay.

\subsection{Western blots}

Western blots were carried out using primary antibodies directed against PSD95 (Rabbit, D27E11, Cell Signaling, Leiden, The Netherlands) and Vinculin (Mouse, V9131, Merck KGaA, 
Darmstadt, Germany) as housekeeping protein. Secondary antibodies coupled with horseradish peroxidase were used for revelation with enhanced chemiluminescence. They were directed against rabbit for PSD95 (7074, Cell Signaling, Leiden, The Netherlands) and mouse for Vinculin (HAF007, R\&D Systems Inc., Minneapolis, USA).

\subsection{Immunohistochemistry}

Fixed hemispheres were dehydrated, included in paraffin and sagitally cut with a microtome at a $5 \mu \mathrm{m}$ thickness. Brain sections were incubated with a primary antibody directed against APP (A4, Cell Signaling, Danvers, USA) and a secondary biotinylated anti-rabbit antibody (Vector Laboratory, Eurobio Scientific, Les Ulis, France). Neurodegeneration was evaluated with Fluoro-Jade B (Merck Millipore, Darmstadt, Germany). Labeling either visible or fluorescent was quantified with automated algorithm on Image $1.48 \mathrm{v}$ (National Institute of Health, USA).

\subsection{Statistical analyses}

The aim of our study was to evaluate the effect of low doses of Brimapitide on pathological features of an AD mice model. As we wanted to find the lowest effective dose, we choose to compare separately each Brimapitide groups to Nacl counterpart and/or control animals. Non-parametric Mann-Whitney U-test was used for comparing each groups (GraphPad Prism, San Diego, USA). For each comparison, $\mathrm{P}$ value $<0.05$ or inferior were considered statistically significant. 


\section{ACKNOWLEDGEMENTS}

The authors thank the XIGEN S. A. and INSERM for funding this work. The authors thank the staff from CDTA-TAAM and PHENO-ICMICE for their technical support.

\section{DISCLOSURE}

Pr. J. Hugon is a consultant for Xigen S.A. and Pr. J. Hugon, Dr. B. Porte and G. Marguerit have received fundings from Xigen S.A.

All authors have approved the final article.

\section{FUNDING SOURCE}

This work was supported by XiGen S.A via INSERM. The company also provided Brimapitide for this study and took part in the decision to submit this work for publication. 


\section{REFERENCES}

Borsello, T., P. G. Clarke, L. Hirt, A. Vercelli, M. Repici, D. F. Schorderet, J. Bogousslavsky and C. Bonny (2003). "A peptide inhibitor of c-Jun N-terminal kinase protects against excitotoxicity and cerebral ischemia." Nat Med 9(9): 1180-1186. 10.1038/nm911

Chiquet, C., F. Aptel, C. Creuzot-Garcher, J. P. Berrod, L. Kodjikian, P. Massin, C. Deloche, J. Perino, B. A. Kirwan, S. de Brouwer, J. M. Combette and F. Behar-Cohen (2017). "Postoperative Ocular Inflammation: A Single Subconjunctival Injection of XG-102 Compared to Dexamethasone Drops in a Randomized Trial." Am J Ophthalmol 174: 76-84. 10.1016/j.ajo.2016.10.012

Coffey, E. T. (2014). "Nuclear and cytosolic JNK signalling in neurons." Nat Rev Neurosci 15(5): 285299. 10.1038/nrn3729

Colombo, A., A. Bastone, C. Ploia, A. Sclip, M. Salmona, G. Forloni and T. Borsello (2009). "JNK regulates APP cleavage and degradation in a model of Alzheimer's disease." Neurobiol Dis 33(3): 518525. 10.1016/j.nbd.2008.12.014

Davoli, E., A. Sclip, M. Cecchi, S. Cimini, A. Carra, M. Salmona and T. Borsello (2014). "Determination of tissue levels of a neuroprotectant drug: the cell permeable JNK inhibitor peptide." J Pharmacol Toxicol Methods 70(1): 55-61. 10.1016/j.vascn.2014.04.001

Deloche, C., L. Lopez-Lazaro, S. Mouz, J. Perino, C. Abadie and J. M. Combette (2014). "XG-102 administered to healthy male volunteers as a single intravenous infusion: a randomized, doubleblind, placebo-controlled, dose-escalating study." Pharmacol Res Perspect 2(1): e00020.

10.1002/prp2.20

Devi, L., M. J. Alldred, S. D. Ginsberg and M. Ohno (2010). "Sex- and brain region-specific acceleration of beta-amyloidogenesis following behavioral stress in a mouse model of Alzheimer's disease." Mol Brain 3: 34.10.1186/1756-6606-3-34

Dinamarca, Margarita, Juvenal Ríos, and Nibaldo Inestrosa (2012). "Postsynaptic Receptors for Amyloid- $\beta$ Oligomers as Mediators of Neuronal Damage in Alzheimer's Disease." Frontiers in Physiology 3: 464. 10.3389/fphys.2012.00464.

Dumurgier, J., F. Mouton-Liger, P. Lapalus, M. Prevot, J. L. Laplanche, J. Hugon, C. Paquet and N. Groupe d'Investigation du Liquide Cephalorachidien Study (2013). "Cerebrospinal fluid PKR level predicts cognitive decline in Alzheimer's disease." PLoS One 8(1): e53587.

10.1371/journal.pone.0053587

Duyckaerts, C., B. Delatour and M. C. Potier (2009). "Classification and basic pathology of Alzheimer disease." Acta Neuropathol 118(1): 5-36. 10.1007/s00401-009-0532-1

Ebenezer, P. J., A. M. Weidner, H. LeVine, 3rd, W. R. Markesbery, M. P. Murphy, L. Zhang, K. Dasuri, S. O. Fernandez-Kim, A. J. Bruce-Keller, E. Gavilan and J. N. Keller (2010). "Neuron specific toxicity of oligomeric amyloid-beta: role for JUN-kinase and oxidative stress." J Alzheimers Dis 22(3): 839-848. 10.3233/jad-2010-101161

Eshraghi, A. A., M. Aranke, R. Salvi, D. Ding, J. K. M. Coleman, Jr., E. Ocak, R. Mittal and T. Meyer (2018). "Preclinical and clinical otoprotective applications of cell-penetrating peptide D-JNKI-1 (AM111)." Hear Res 368: 86-91. 10.1016/j.heares.2018.03.003

Jadiya, Pooja, Devin W. Kolmetzky, Dhanendra Tomar, Antonio Di Meco, Alyssa A. Lombardi, Jonathan P. Lambert, Timothy S. Luongo, Marthe H. Ludtmann, Domenico Pratico, and John W. Elrod. (2019). "Impaired Mitochondrial Calcium Efflux Contributes to Disease Progression in Models of Alzheimer's Disease." Nat Commun 10(1):3885. 10.1038/s41467-019-11813-6. 
GBD 2016 Dementia Collaborators. (2019). "Global, regional, and national burden of Alzheimer's disease and other dementias, 1990-2016: a systematic analysis for the Global Burden of Disease Study 2016." Lancet Neurol 18(1): 88-106. 10.1016/s1474-4422(18)30403-4

Gourmaud, S., C. Paquet, J. Dumurgier, C. Pace, C. Bouras, F. Gray, J. L. Laplanche, E. F. Meurs, F. Mouton-Liger and J. Hugon (2015). "Increased levels of cerebrospinal fluid JNK3 associated with amyloid pathology: links to cognitive decline." J Psychiatry Neurosci 40(3): 151-161.

Gourmaud, S., F. Mouton-Liger, C. Abadie, E. F. Meurs, C. Paquet and J. Hugon (2016). "Dual Kinase Inhibition Affords Extended in vitro Neuroprotection in Amyloid-beta Toxicity." J Alzheimers Dis 54(4): 1659-1670.10.3233/JAD-160509

Gourmaud, S., P. Thomas, S. Thomasseau, M. Tible, C. Abadie, C. Paquet and J. Hugon (2018). "Brimapitide Reduced Neuronal Stress Markers and Cognitive Deficits in 5XFAD Transgenic Mice." J Alzheimers Dis 63(2): 665-674. 10.3233/JAD-171099

Grinan-Ferre, C., S. Sarroca, A. Ivanova, D. Puigoriol-Illamola, F. Aguado, A. Camins, C. Sanfeliu and M. Pallas (2016). "Epigenetic mechanisms underlying cognitive impairment and Alzheimer disease hallmarks in 5XFAD mice." Aging (Albany NY) 8(4): 664-684. 10.18632/aging.100906

Hardy, J. A. and G. A. Higgins (1992). "Alzheimer's disease: the amyloid cascade hypothesis." Science 256(5054): 184-185.

Hugon, J., F. Mouton-Liger, J. Dumurgier and C. Paquet (2017). "PKR involvement in Alzheimer's disease." Alzheimers Res Ther 9(1): 83. 10.1186/s13195-017-0308-0

Jing, H., X. Zhang, M. Gao, K. Luo, W. Fu, M. Yin, W. Wang, Z. Zhu, J. Zheng and X. He (2019). "Kartogenin preconditioning commits mesenchymal stem cells to a precartilaginous stage with enhanced chondrogenic potential by modulating JNK and beta-catenin-related pathways." FASEB J 33(4): 5641-5653.10.1096/fj.201802137RRR

Kaminska, B., A. Gozdz, M. Zawadzka, A. Ellert-Miklaszewska and M. Lipko (2009). "MAPK signal transduction underlying brain inflammation and gliosis as therapeutic target." Anat Rec (Hoboken) 292(12): 1902-1913. 10.1002/ar.21047

Kim, E. K. and E. J. Choi (2015). "Compromised MAPK signaling in human diseases: an update." Arch Toxicol 89(6): 867-882. 10.1007/s00204-015-1472-2

Lane, C. A., J. Hardy and J. M. Schott (2018). "Alzheimer's disease." Eur J Neurol 25(1): 59-70. 10.1111/ene.13439

Morishima, Y., Y. Gotoh, J. Zieg, T. Barrett, H. Takano, R. Flavell, R. J. Davis, Y. Shirasaki and M. E. Greenberg (2001). "Beta-amyloid induces neuronal apoptosis via a mechanism that involves the c-Jun N-terminal kinase pathway and the induction of Fas ligand." J Neurosci 21(19): 7551-7560.

Nair, A. B. and S. Jacob (2016). "A simple practice guide for dose conversion between animals and human." J Basic Clin Pharm 7(2): 27-31.10.4103/0976-0105.177703

Oakley, H., S. L. Cole, S. Logan, E. Maus, P. Shao, J. Craft, A. Guillozet-Bongaarts, M. Ohno, J. Disterhoft, L. Van Eldik, R. Berry and R. Vassar (2006). "Intraneuronal beta-amyloid aggregates, neurodegeneration, and neuron loss in transgenic mice with five familial Alzheimer's disease mutations: potential factors in amyloid plaque formation." J Neurosci 26(40): 10129-10140. 10.1523/JNEUROSCI.1202-06.2006

Patterson, C. (2018). "World Alzheimer Report 2018." Alzheimer Disease International.

Ploia, C., X. Antoniou, A. Sclip, V. Grande, D. Cardinetti, A. Colombo, N. Canu, L. Benussi, R. Ghidoni, G. Forloni and T. Borsello (2011). "JNK plays a key role in tau hyperphosphorylation in Alzheimer's disease models." J Alzheimers Dis 26(2): 315-329. 10.3233/JAD-2011-110320 
Repici, M., L. Mare, A. Colombo, C. Ploia, A. Sclip, C. Bonny, P. Nicod, M. Salmona and T. Borsello (2009). "c-Jun N-terminal kinase binding domain-dependent phosphorylation of mitogen-activated protein kinase kinase 4 and mitogen-activated protein kinase kinase 7 and balancing cross-talk between c-Jun $\mathrm{N}$-terminal kinase and extracellular signal-regulated kinase pathways in cortical neurons." Neuroscience 159(1): 94-103.10.1016/j.neuroscience.2008.11.049

Savage, M. J., Y. G. Lin, J. R. Ciallella, D. G. Flood and R. W. Scott (2002). "Activation of c-Jun Nterminal kinase and p38 in an Alzheimer's disease model is associated with amyloid deposition." J Neurosci 22(9): 3376-3385.20026352

Sclip, A., X. Antoniou, A. Colombo, G. G. Camici, L. Pozzi, D. Cardinetti, M. Feligioni, P. Veglianese, F. H. Bahlmann, L. Cervo, C. Balducci, C. Costa, A. Tozzi, P. Calabresi, G. Forloni and T. Borsello (2011). "c-Jun N-terminal kinase regulates soluble Abeta oligomers and cognitive impairment in AD mouse model." J Biol Chem 286(51): 43871-43880. 10.1074/jbc.M111.297515

Sclip, A., A. Tozzi, A. Abaza, D. Cardinetti, I. Colombo, P. Calabresi, M. Salmona, E. Welker and T. Borsello (2014). "c-Jun N-terminal kinase has a key role in Alzheimer disease synaptic dysfunction in vivo." Cell Death Dis 5: e1019.10.1038/cddis.2013.559

Staecker, H., G. Jokovic, S. Karpishchenko, A. Kienle-Gogolok, A. Krzyzaniak, C. D. Lin, P. Navratil, V. Tzvetkov, N. Wright and T. Meyer (2019). "Efficacy and Safety of AM-111 in the Treatment of Acute Unilateral Sudden Deafness-A Double-blind, Randomized, Placebo-controlled Phase 3 Study." Otol Neurotol. 10.1097/mao.0000000000002229

Standen, C. L., J. Brownlees, A. J. Grierson, S. Kesavapany, K. F. Lau, D. M. McLoughlin and C. C. Miller (2001). "Phosphorylation of thr(668) in the cytoplasmic domain of the Alzheimer's disease amyloid precursor protein by stress-activated protein kinase 1 b (Jun N-terminal kinase-3)." J Neurochem 76(1): 316-320.

Tamagno, E., M. Parola, P. Bardini, A. Piccini, R. Borghi, M. Guglielmotto, G. Santoro, A. Davit, O. Danni, M. A. Smith, G. Perry and M. Tabaton (2005). "Beta-site APP cleaving enzyme up-regulation induced by 4-hydroxynonenal is mediated by stress-activated protein kinases pathways." J Neurochem 92(3): 628-636. 10.1111/j.1471-4159.2004.02895.x

Webster, S. J., A. D. Bachstetter, P. T. Nelson, F. A. Schmitt and L. J. Van Eldik (2014). "Using mice to model Alzheimer's dementia: an overview of the clinical disease and the preclinical behavioral changes in 10 mouse models." Front Genet 5: 88. 10.3389/fgene.2014.00088

Wei, Z. Z., S. P. Yu, J. H. Lee, D. Chen, T. M. Taylor, T. C. Deveau, A. C. Yu and L. Wei (2014).

"Regulatory role of the JNK-STAT1/3 signaling in neuronal differentiation of cultured mouse embryonic stem cells." Cell Mol Neurobiol 34(6): 881-893.10.1007/s10571-014-0067-4

Yarza, R., S. Vela, M. Solas and M. J. Ramirez (2015). "c-Jun N-terminal Kinase (JNK) Signaling as a Therapeutic Target for Alzheimer's Disease." Front Pharmacol 6: 321. 10.3389/fphar.2015.00321

Zhu, X., A. K. Raina, C. A. Rottkamp, G. Aliev, G. Perry, H. Boux and M. A. Smith (2001). "Activation and redistribution of $\mathrm{c}$-jun $\mathrm{N}$-terminal kinase/stress activated protein kinase in degenerating neurons in Alzheimer's disease." J Neurochem 76(2): 435-441. 


\section{FIGURES LEGENDES}

Figure 1. Effect of Brimapitide treatment on spatial and procedural working memory in the Y-maze test. Data are represented as means \pm SEM. ${ }^{*} \mathrm{P}<0.05, * * * \mathrm{P}<0.001, \mathrm{Xg}-102=$ Brimapitide

Figure 2. Effect of Brimapitide treatment on neuronal impairments. A) Quantification of FluoroJade (FJ) labelling of degenerating neurons in subiculum. B) Level of PSD95 in the hippocampus. Data are represented as means \pm SEM. ${ }^{*} \mathrm{P}<0.05, * * \mathrm{P}<0.01, \mathrm{Xg}-102=$ Brimapitide

Figure 3. Effect of Brimapitide treatment on amyloid burden. Quantification of $A \beta 42$ clone A4 labelling in A) the cortex and B) the subiculum. Data are represented as means \pm SEM. ${ }^{*} \mathrm{P}<0.05, * * * \mathrm{P}<0.001, * * * * \mathrm{P}<0.0001, \mathrm{Xg}-102=$ Brimapitide 


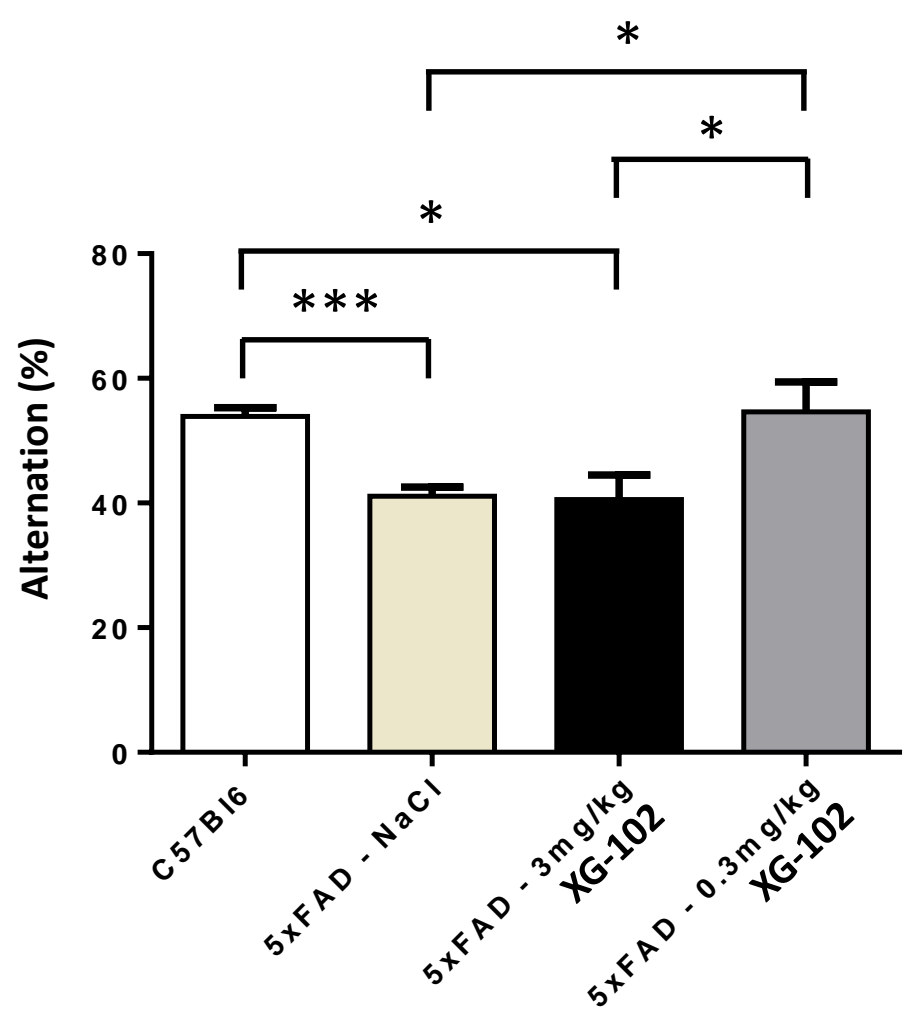


A)

$* *$



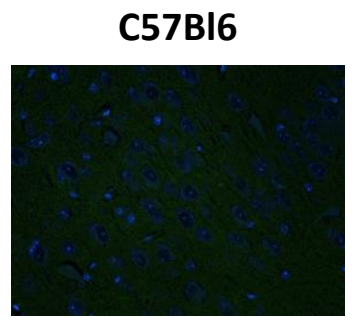

3mg XG-102



Nacl



0.3mg XG-102

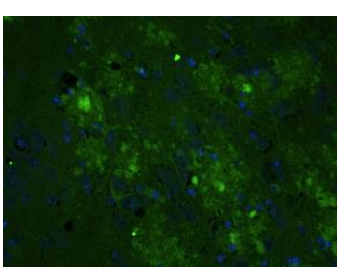

B)




A)

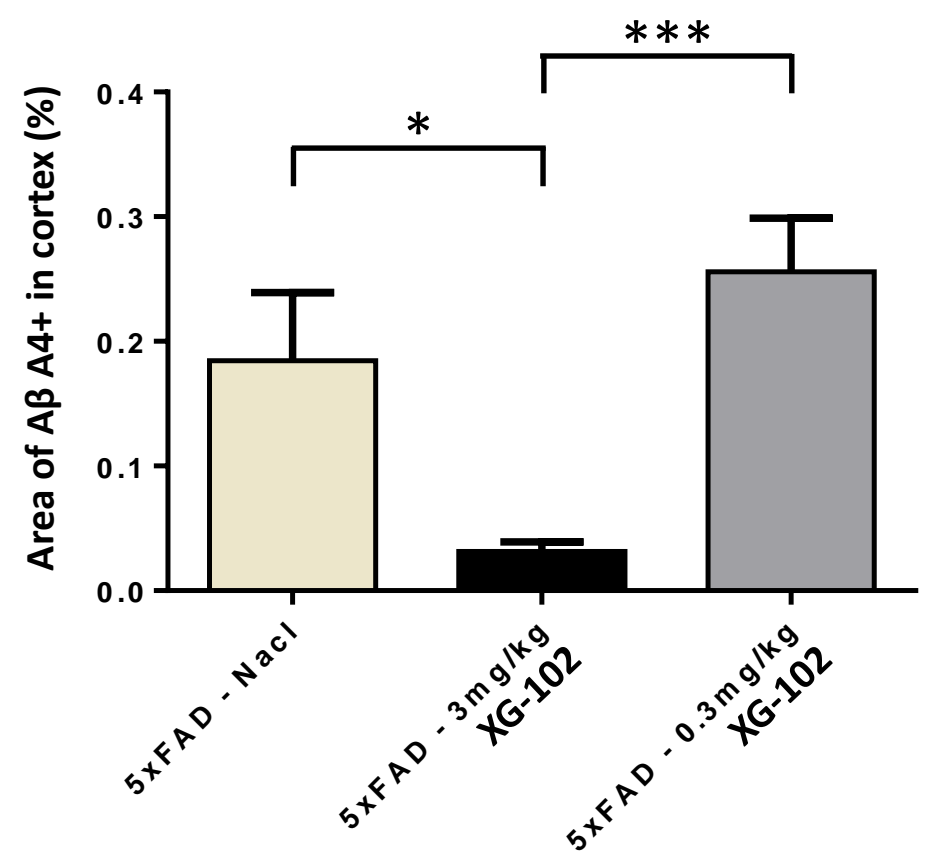

B)

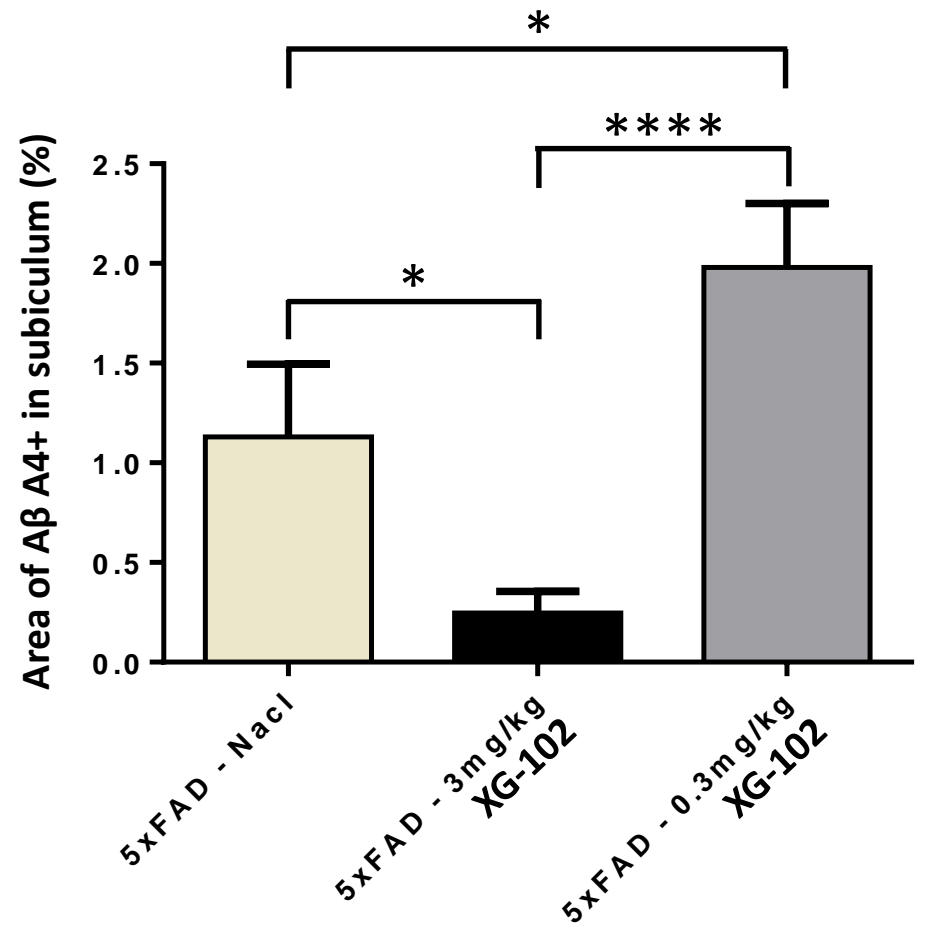

C57BI6
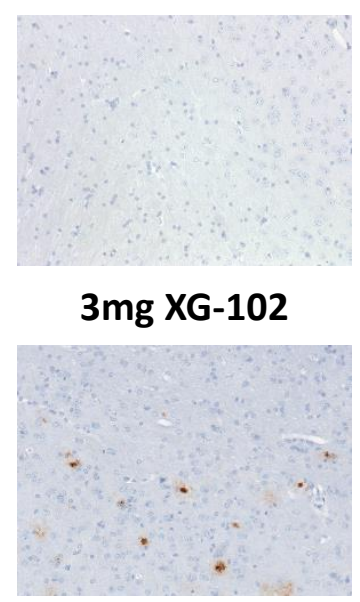

C57BI6

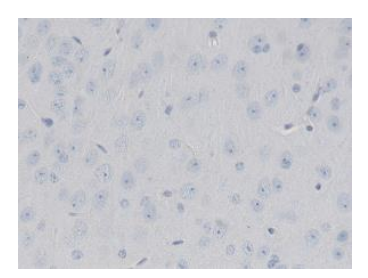

3mg XG-102

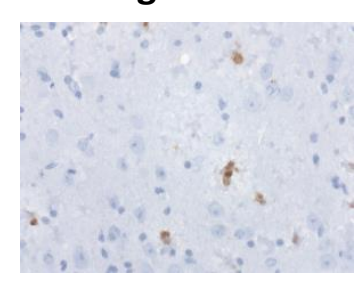

Nacl

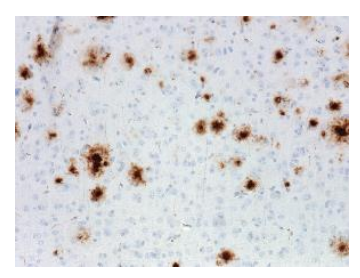

0.3mg XG-102

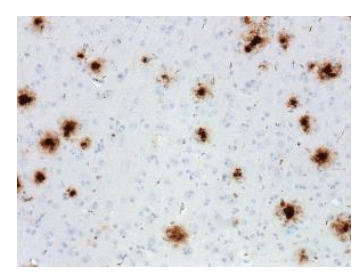

Nacl

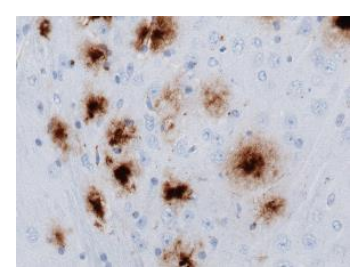

0.3mg XG-102

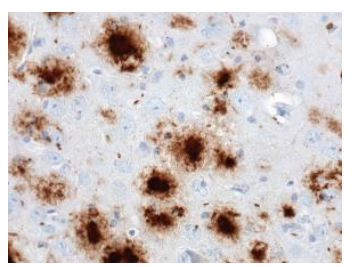

